\title{
Educação não-formal, participação da sociedade civil e estruturas colegiadas nas escolas
}

Maria da Glória Gohn

\section{Resumo}

O trabalho apresenta um estudo sobre a educação não-formal e seu papel no processo educativo mais geral. Considera-se a educação não-formal como uma área de conhecimento ainda em construção. Estuda-se a possibilidade deste processo em conselhos de escolas e o aprendizado que resulta da participação da sociedade civil nestes conselhos. O trabalho se divide em duas partes: a primeira tem caráter teórico e discute a categoria educação não-formal em si, seu campo e atributos. Por meio da análise comparativa, busca-se diferenciá-la da educação formal e da educação informal. A segunda investiga a categoria da educação não - formal em conselhos escolares, e em movimentos sociais que atuam na área da educação.

Palavras-chave: Educação não-formal. Educação formal. Educação informal. Conselhos participativos. Participação da sociedade civil. ConseIhos de escolas.

\section{Abstract \\ Non-formal education, civil society participation and councils structures in the schools}

The paper presents a study about the non-formal education and its role in the wide educative process. It considers the non-formal education as an area of knowledge still in construction. It studies the possibility of this educational process in the councils of schools and the learning that results from the civil society participation in these councils. The paper has two parts: the first has a theoretical character and discusses the non-formal category, distinguishing it from the formal and informal education categories. The second one investigates the non-formal category in the councils of the schools and in the social movements acting in the educational area. 
Keywords: Non-formal education. Formal education. Informal education. Participative councils. Civil society participation. Council school.

\section{Resumen}

\section{Educación no-formal,} participación de la sociedad civil y estructuras de consejos en las escuelas

El objectivo de este trabajo es realizar un estudio sobre la educación no-formal y sus roles en el proceso de educación más general. La educación no-formal es un campo de conecimiento todavía en construcción. El trabajo investiga la posibilidad del proceso de educación no-formal en los consejos de las escuelas, y hace un análisis de las aprendizajes que estas experiencias generan hacia los consejeros. El trabajo fue ordenado en dos partes: la primera tiene un carácter teórico y discute la categoría educación no-formal, haciendo distinción de la educación formal y de la educación informal. La segunda investiga la categoría no-formal, en los consejos de las escuelas y en los movimientos sociales del area educacional.

Palabras clave: Educación noformal. Educación formal. Educación informal. Consejos participativos. Sociedad civile. Consejos de las escuelas.

A educação não-formal designa um processo com várias dimensões tais como: a aprendizagem política dos direitos dos indivíduos enquanto cidadãos; a capacitação dos indivíduos para o trabalho, por meio da aprendizagem de habilidades e/ ou desenvolvimento de potencialidades; a aprendizagem e exercício de práticas que capacitam os indivíduos a se organizarem com objetivos comunitários, voltadas para a solução de problemas coletivos cotidianos; a aprendizagem de conteúdos que possibilitem aos indivíduos fazerem uma leitura do mundo do ponto de vista de compreensão do que se passa ao seu redor; a educação desenvolvida na mídia e pela mídia, em especial a eletrônica etc.

Quando tratamos da educação nãoformal, a comparação com a educação formal é quase que automática. $\bigcirc$ termo não-formal também é usado por alguns investigadores como sinônimo de informal. Consideramos que é necessário distinguir e demarcar as diferenças entre estes conceitos. A princípio podemos demarcar seus campos de desenvolvimento: a educação formal é aquela desenvolvida nas escolas, com conteúdos previamente demarcados; a informal como aquela que os indivíduos aprendem durante seu processo de socialização - na família, bairro, clube, amigos etc., carregada de valores e culturas próprias, de pertencimento e sentimentos herdados: e a educação não-formal é aquela que se aprende "no mundo da vida", via os processos de compartilhamento de experiências, principalmente em espaços e ações coletivos cotidianas. Vamos tentar demarcar melhor essas diferenças por meio uma série de questões, que são, aparentemente, extremamente simples, mas nem por isso simplificadoras da realidade, a saber:

"Quem é o educador em cada campo 
de educação que estamos tratando? Em cada campo, quem educa é o agente do processo de construção do saber?"

Na educação formal sabemos que são os professores. Na não-formal, o grande educador é o "outro", aquele com quem interagimos ou nos integramos. Na educação informal, os agentes educadores são os pais, a família em geral, os amigos, os vizinhos, colegas de escola, a igreja paroquial, os meios de comunicação de massa, etc.

"Onde se educa? Qual é o espaço físico territorial onde transcorrem os atos e os processos educativos?"

$\mathrm{Na}$ educação formal estes espaços são os do território das escolas, são instituições regulamentadas por lei, certificadoras, organizadas segundo diretrizes nacionais. $\mathrm{Na}$ educação não-formal, os espaços educativos localizam-se em territórios que acompanham as trajetórias de vida dos grupos e indivíduos, fora das escolas, em locais informais, locais onde há processos interativos intencionais ( a questão da intencionalidade é um elemento importante de diferenciação). Já a educação informal tem seus espaços educativos demarcados por referências de nacionalidade, localidade, idade, sexo, religião, etnia etc. A casa onde se mora, a rua, o bairro, o condomínio, o clube que se freqüenta, a igreja ou o local de culto a que se vincula sua crença religiosa, o local onde se nasceu, etc.

"Como se educa? Em que situação, em qual contexto?"

A educação formal pressupõe ambientes normatizados, com regras e padrões comportamentais definidos previamente. A não -formal ocorre em ambientes e situações interativos construídos coletivamente, segundo diretrizes de dados grupos, usualmente a participação dos indivíduos é optativa, mas ela também poderá ocorrer por forças de certas circunstâncias da vivência histórica de cada um. Há na educação não-formal uma intencionalidade na ação, no ato de participar, de aprender e de transmitir ou trocar saberes. A informal opera em ambientes espontâneos, onde as relações sociais se desenvolvem segundo gostos, preferências, ou pertencimentos herdados.

"Qual a finalidade ou objetivos de cada um dos campos de educação assinaladas?"

$\mathrm{Na}$ educação formal, entre outros objetivos destacam-se os relativos ao ensino e aprendizagem de conteúdos historicamente sistematizados, normatizados por leis, dentre os quais destacam-se o de formar o indivíduo como um cidadão ativo, desenvolver habilidades e competências várias, desenvolver a criatividade, percepção, motricidade etc. A educação informal socializa os indivíduos, desenvolve hábitos, atitudes, comportamentos, modos de pensar e de se expressar no uso da linguagem, segundo valores e crenças de grupos que se freqüenta ou que pertence por herança, desde o nascimento Trata-se do processo de socialização dos indivíduos. A educação não-formal capacita os indivíduos a se tornarem cidadãos do mundo, no mundo. Sua finalidade é abrir janelas de conhecimento sobre o mundo que circunda os indivíduos e suas relações sociais. Seus objetivos não são dados a priori, eles se constróem no processo interativo, gerando um processo educativo. Um modo de educar surge como resultado do processo voltado para os interesses e as necessidades 
que dele participa. A construção de relações sociais baseadas em princípios de igualdade e justiça social, quando presentes num dado grupo social, fortalece o exercício da cidadania. A transmissão de informação e formação política e sociocultural é uma meta na educação não formal. Ela prepara os cidadãos, educa o ser humano para a civilidade, em oposição à barbárie, ao egoísmo, individualismo etc..

"Quais são os principais atributos de cada uma das modalidades educativas que estamos diferenciando?"

A educação formal requer tempo, local específico, pessoal especializado, organização de vários tipos (inclusive a curricular), sistematização seqüencial das atividades, disciplinamento, regulamentos e leis, órgãos superiores etc. Ela tem caráter metódico e, usualmente, divide-se por idade/ classe de conhecimento. A educação informal não é organizada, os conhecimentos não são sistematizados e são repassados a partir das práticas e experiência anteriores, usualmente é o passado orientando o presente. Ela atua no campo das emoções e sentimentos. É um processo permanente e não organizado. A educação não -formal tem outros atributos: ela não é, organizada por séries/idade/conteúdos; atua sobre aspectos subjetivos do grupo; trabaIha e forma a cultura política de um grupo. Desenvolve laços de pertencimento. Ajuda na construção da identidade coletiva do grupo (este é um dos grandes destaques da educação não-formal na atualidade); ela pode colaborar para o desenvolvimento da auto-estima e do empowerment do grupo, criando o que alguns analistas denominam, o capital social de um grupo. Fundamenta-se no critério da solidarieda- de e identificação de interesses comuns e é parte do processo de construção da cidadania coletiva e pública do grupo.

"Quais são os resultados esperados em cada campo assinalado?"

Na educação formal espera-se, sobretudo que haja uma aprendizagem efetiva (que, infelizmente nem sempre ocorre), além da certificação e titulação que capacitam os indivíduos a seguir para graus mais avançados. Na educação informal os resultados não são esperados, eles simplesmente acontecem a partir do desenvolvimento do senso comum nos indivíduos, senso este que orienta suas formas de pensar e agir espontaneamente. A educação não-formal poderá desenvolver, como resultados, uma série de processos tais como:

- consciência e organização de como agir em grupos coletivos;

- A construção e reconstrução de concepção (ões) de mundo e sobre o mundo;

- contribuição para um sentimento de identidade com uma dada comunidade;

- forma o indivíduo para a vida e suas adversidades (e não apenas capacitao para entrar no mercado de trabalho);

- quando presente em programas com crianças ou jovens adolescentes a educação não-formal resgata o sentimento de valorização de si próprio (o que a mídia e os manuais de auto-ajuda denominam, simplificadamente, como a auto-estima); ou seja dá condições aos indivíduos para desenvolverem sentimentos de auto-valorização, de rejeição dos preconceitos que lhes são dirigidos, o desejo de lutarem para ser reconhecidos como iguais (enquanto seres humanos), dentro de suas diferenças (raciais, étnicas, reli- 
giosas, culturais, etc.);

- os indivíduos adquirem conhecimento de sua própria prática, os indivíduos aprendem a ler e interpretar o mundo que os cerca.

\section{Algumas características da educação não-formal: metas, lacunas e metodologias}

A seguir listamos algumas características que a educação não formal pode atingir em termos de metas, em processos planejados de ações coletivas grupais:

- O aprendizado da diferenças. Aprende-se a conviver com demais. Socializa-se o respeito mútuo;

- Adaptação do grupo a diferentes culturas, reconhecimento dos indivíduos e do papel do outro, trabalha o "estranhamento";

- Construção da identidade coletiva de um grupo;

- Balizamento de regras éticas relativas às condutas aceitáveis socialmente.

que falta na educação não-formal:

- Formação específica a educadores a partir da definição de seu papel e as atividades a realizar;

- Definição mais clara de funções e objetivos da educação não formal;

- Sistematização das metodologias utilizadas no trabalho cotidiano;

- Construção de metodologias que possibilitem o acompanhamento do trabalho que vem sendo realizado;

- Construção de instrumentos metodológicos de avaliação e análise do trabalho realizado;

- Construção de metodologias que pos- sibilitem o acompanhamento do trabalho de egressos que participaram de programas de educação não formal;

- Criação de metodologias e indicadores para estudo e análise de trabaIhos da Educação não formal em campos não sistematizados. Aprendizado gerado por atos de vontade do receptor tais como a aprendizagem via Internet, para aprender música, tocar um instrumento etc.;

- Mapeamento das formas de educação não formal na auto aprendizagem dos cidadãos (principalmente jovens).

\section{Metodologias}

A questão da metodologia merece um destaque porque é um dos pontos mais fracos na educação não-formal e a comparação com as outras modalidades educativas que utilizamos no item anterior não resolve muito. De toda forma, na educação formal as metodologias são, usualmente, planificada previamente segundo conteúdos prescritos nas leis. As metodologias de desenvolvimento do processo ensino/aprendizagem são compostas por um leque grande de modalidades, temas e problemas e não vamos adentrar neste debate porque não é nossa área de conhecimento. A educação informal tem como método básico a vivência e a reprodução do conhecido, a reprodução da experiência segundo os modos e as formas como foram apreendidas e codificadas. Na educação não-formal, as metodologias operadas no processo de aprendizagem parte da cultura dos indivíduos e dos grupos. $\bigcirc$ método nasce a partir de problematização da vida cotidiana; os conteúdos emergem a partir dos temas que se colocam como necessidades, carências, desafios, obstáculos ou ações empreendedoras a serem realizadas; os 
conteúdos não são dados a priori. São construídos no processo. $\bigcirc$ método passa pela sistematização dos modos de agir e de pensar o mundo que circunda as pessoas. Penetra-se portanto no campo do simbólico, das orientações e representações que conferem sentido e significado às ações humanas. Supõe a existência da motivação das pessoas que participam. Ela não se subordina às estruturas burocráticas. É dinâmica. Visa à formação integral dos indivíduos. Neste sentido tem um caráter humanista. Ambiente não formal e mensagens veiculadas "falam ou fazem chamamentos" às pessoas e aos coletivos, e as motivam. Mas como há intencionalidades nos processos e espaços da educação não-formal, há caminhos, percursos, metas, objetivos estratégicos que podem se alterar constantemente. Há metodologias, em suma, que precisam ser desenvolvidas, codificadas, ainda que com alto grau de provisoriedade pois o dinamismo, a mudança, o movimento da realidade segundo o desenrolar dos acontecimentos, são as marcas que singularizam a educação não-formal.

Qualquer que seja o caminho metodológico construído ou reconstruído, é de suma importância atentar para o papel dos agentes mediadores no processo: os educadores, os mediadores, assessores, facilitadores, monitores, referências, apoios ou qualquer outra denominação que se dê para os indivíduos que trabalham com grupos organizados ou não. Eles são fundamentais na marcação de referenciais no ato de aprendizagem, eles carregam visões de mundo, projetos societários, ideologias, propostas, conhecimentos acumulados etc. Eles se confrontarão com os outros participantes do processo educativo, estabelecerão diálogos, conflitos, ações solidárias etc. Eles se destacam no conjunto e por meio deles podemos conhecer o projeto socioeducativo do grupo, a visão de mundo que estão construindo, os valores defendidos e os que são rejeitados. Qual o projeto político-cultural do grupo, em suma.

Para finalizar a primeira parte deste texto destacamos que também diferenciamos a educação não- formal de outras propostas de educação, apresentadas como educação social, no século $X X$, porque a maioria daquelas propostas ao se dirigirem para os excluídos objetivam, na maior parte das vezes, apenas inseri-los no mercado de trabalho. Entendemos a educação não - formal como aquela voltada para o ser humano como um todo, cidadão do mundo, homens e mulheres. Em hipótese alguma ela substitui ou compete com a Educação Formal, escolar. Poderá ajudar na complementação dessa última, via programações específicas, articulando escola e comunidade educativa localizada no território de entorno da escola. A educação não- formal tem alguns de seus objetivos próximos da educação formal, como a formação de um cidadão pleno, mas ela tem também a possibilidade de desenvolver alguns objetivos que thes são específicos, via a forma e espaços onde se desenvolvem suas práticas, a exemplo de um conselho ou a participação em uma luta social, contra as discriminações, por exemplo, a favor das diferenças culturais etc. Resumidamente podemos enumerar os objetivos da educação não-formal como sendo:

a) Educação para cidadania;

b) Educação para justiça social;

c) Educação para direitos (humanos, sociais, políticos, culturais, etc.);

d) Educação para liberdade;

e) Educação para igualdade;

f) Educação para democracia; 
g) Educação contra discriminação;

h) Educação pelo exercício da cultura, e para a manifestação das diferenças culturais.

\section{A educação não-formal em ação: conselhos e colegiados na escola: espaços de educação não-formal}

Observa-se que inúmeras inovações no campo democrático advêm das práticas geradas pela sociedade civil que alteram a relação estado-sociedade ao longo do tempo e constróem novas formas políticas de agir, especialmente na esfera pública não estatal. De fato, são inúmeras as novas práticas sociais expressas em novos formatos institucionais da participação, tais como os conselhos, os fóruns, as assembléias populares e as parcerias. Em todas elas a educação não-formal está presente, como processo de aprendizagem de saberes aos e entre seus participantes.

Ao analisarmos as possibilidades de participação da comunidade educativa em uma escola, articulando-a aos processos de aprendizagem não-formal que os métodos de gestão participativa desenvolvem, não podemos deixar de tecer algumas considerações sobre as estruturas de participação que já existem no interior das escolas, a exemplo dos distintos e diferenciados colegiados e conselhos. Nos conselhos se entrecruzam necessidades advindas da prática da educação formal/escolar, com a educação não-formal, principalmente no que se refere a participação dos pais e outros membros da comunidade educativa nas suas reuniões.

Observa-se que o processo brasileiro de descentralização da educação não descentralizou, de fato, o poder no interior das escolas. Usualmente, esse poder continua nas mãos da diretora ou gestora, que o monopoliza, faz a pauta das reuniões dos conselhos e colegiados escolares, não a divulga com antecedência etc. A comunidade externa e os pais não dispõem de tempo e, muitas vezes, nem avaliam a relevância de participar ou de estarem presentes nas reuniões. Além disso, usualmente, esses pais não estão preparados para entender as questões do cotidiano das reuniões, como as orçamentárias. Só exercem uma participação ativa nos colegiados aqueles pais com experiência participativa anterior, extra-escolar, revelando a importância da participação dos cidadãos (ãs) em ações coletivas na sociedade civil. $\bigcirc$ caráter educativo que essa participação adquire, quando ela ocorre em movimentos sociais comunitários, organizados em função de causas públicas, prepara os indivíduos para atuarem como representantes da sociedade civil organizada. E os colegiados escolares são uma dessas instâncias.

Muitos funcionários das escolas são membros dos conselhos e dos colegiados escolares mas, usualmente, exercitam um pacto do silêncio, não participando de fato e servindo de "modelo passivo" para outros setores da comunidade educativa que compõem um colegiado. Por que eles se comportam assim? Porque, na maioria dos casos, estão presentes para referendar demandas corporativas, ou para fortalecer diretorias centralizadoras. Como elo mais fraco do poder, eles participam para 'compor', para dar número e quorum necessários aos colegiados, contribuindo com esse comportamento para não construir nada e nada mudar.

Por que isso ocorre? Porque, embora 
os colegiados sejam um espaço legítimo e de direito, e uma conquista para o exercício da cidadania, até por serem previstos em lei, essa cidadania tem que ser qualificada e construída na prática. Os projetos políticos dos representantes dos diferentes segmentos e grupos, seus valores, visões de mundo etc. interferem na dinâmica desses processos participativos. Para terem como meta projetos emancipatórios, eles devem ter como lastro de suas ações os princípios da igualdade e da universalidade. Os colegiados devem construir ou desenvolver essa sensibilidade por meio de um conjunto de valores que venham a ser refletidos em suas práticas. Sem isso, temos uma inclusão excludente: aumento do número de alunos nas escolas e estruturas descentralizadas que não ampliam de fato a intervenção da comunidade na escola. Temos setores que pretensamente estão representando o interesse público, mas que na realidade defendem o interesse de grupos e corporações, ou a manutenção do poder tradicional, cujo papel é exercer o controle, a vigilância em razão de uma falsa participação ordeira e voltada para a responsabilização da comunidade (pais, mães e outros mais ) nas ações em que o Estado se omite (SILVA, 2003).

Não se deve perder de vista que, por intermédio dos Conselhos, a sociedade civil exercita o direito de participar da gestão de diferentes políticas públicas, tendo a possibilidade de exercer maior controle sobre o Estado. Os fóruns são frutos das redes tecidas nos anos 70/80 que possibilitaram aos grupos organizados olhar para além da dimensão do local; têm abrangência nacional e são fontes de referência e comparação para os próprios participantes. As assembléias e plenárias têm ganha- do formatos variados que vão de encontros regulares e periódicos entre especialistas, interessados e gestores públicos, como no caso da saúde, a observatórios e grupos semi-institucionalizados do orçamento participativo. As novas práticas constituem, assim, um novo tecido social denso e diversificado, tencionam as velhas formas de fazer política e criam novas possibilidades concretas para o futuro, em termos de opções democráticas. As novas práticas de interação escola/representantes da sociedade civil organizada devem ser examinadas à luz dos processos da educação nãoformal caracterizados na primeira parte deste texto. São aprendizagens que estão gerando saberes. Processos difíceis, tensionados mas educativos para todos, pelo que trazem de novo, pela resistência ou pela reiteração obstinada do velho, que não quer ceder à pressão das novas forças.

\section{Movimentos sociais na área da educação}

Cumpre mencionar, no campo dos movimentos sociais enquanto uma área de aprendizagem da educação não-formal, a luta pela educação. Essa luta nunca teve grande visibilidade como um ator independente, pois suas demandas foram, freqüentemente, incorporadas pelos sindicatos dos professores e demais profissionais da educação, ou por articulações mais amplas, como a luta pela educação desenvolvida, no período da Constituinte, pelo Fórum Nacional de Luta pela Escola Pública. As reformas neoliberais realizadas nas escolas públicas de ensino fundamental e médio, na década de 90, alteraram o cotidiano das escolas e deram as bases para a mobilização de novas lutas e movimentos pela educação. Falta de vagas, filas para matrículas, resultados de exames nacionais, progressões continuadas 
(passagem de ano sem exames), deslocamento de alunos de uma mesma família para diferentes escolas, atrasos nos repasses de verbas para merendas escolares, denúncias de fraudes no uso dos novos fundos de apoio à educação (especialmente o FUNDEF), entre outras, foram pautas da agenda do movimento na área da educação. Registre-se ainda que a crise econômica e o desemprego obrigaram centenas de famílias das camadas médias a procurar vagas nas escolas públicas. Além de aumentar a demanda, essas famílias estavam acostumadas a acompanhar mais o cotidiano das escolas de seus filhos, desenvolvendo essas práticas na escola pública, antes mais fechada à participação dos pais. Com isso, em muitos bairros, as escolas passaram a desempenhar o papel de centros comunitários, pois a falta de verbas e a busca de solução para novos problemas como a segurança, a violência entre os jovens e o universo das drogas levou-as à busca de parcerias, no bairro ou na região, com outros organismos e associações organizadas. Assim, as escolas passaram a ser, além de espaços de formação e aprendizagem da educação formal, centros de desenvolvimento da educação não-formal, agentes de construção de territórios civilizatórios, articuladoras de ações que retomem o sentido da civilidade humana. No entanto, essa influência não advém apenas de uma tendência da escola em direção ao bairro: no interior da escola também existem novos espaços de participação, tais como os distintos conselhos tratados acima.

Tendo em vista que um dos principais sujeitos da sociedade civil organizada são os movimentos sociais, é importante registrar que os movimentos pela educação têm caráter histórico, são processuais e ocorrem, portanto, dentro e fora de escolas e em outros espaços institucionais. As lutas pela educação envolvem a luta por direitos e são parte da construção da cidadania. Movimentos sociais pela educação abrangem questões tanto de conteúdo escolar quanto de gênero, etnia, nacionalidade, religiões, portadores de necessidades especiais, meio ambiente, qualidade de vida, paz, direitos humanos, direitos culturais etc. Esses movimentos são fontes e agências de produção de saberes. $\bigcirc$ tema dos direitos é fundamental porque ele dá universalidade às questões sociais, aos problemas econômicos e às políticas públicas, atribuindo-lhes caráter emancipatório. É a partir dos direitos que fazemos o resgate da cultura de um povo e de uma nação, especialmente em tempos neoliberais que destróem ou massificam as culturas locais, regionais ou nacionais. Partir da ótica dos direitos de um povo ou agrupamento social é adotar um princípio ético, moral, baseado nas necessidades e experiência acumulada historicamente dos seres humanos e não nas necessidades do mercado. A ótica dos direitos possibilita-nos a construção de uma agenda de investigação que gera sinergias e não compaixão, que resultam em políticas emancipadoras e não compensatórias. Fora da ótica da universalidade dos direitos caímos nas políticas focalizadas, meras justificativas para políticas que promovem uma modernização conservadora. A ótica dos direitos como ponto de partida poderá nos fazer entender as mudanças sociais em curso.

Listamos, a seguir, alguns dos principais eixos das demandas pela educação nos movimentos sociais envolvendo as escolas. A cada luta corresponde um momento do processo de aprendizagem, típico da educação não-formal, a saber:

- Lutas pelo acesso; 
- Aumento de vagas;

- Escola pública com qualidade;

- Gestão democrática da escola;

- Escola com projetos pedagógicos que respeitem as culturas locais;

- Valor das mensalidades das escolas particulares;

- Por políticas públicas;

- Realização de experiências alternativas;

- Luta no processo de implantação de novos modelos, experiências ou reformas educacionais, envolvendo organização, trajetória das experiências, acompanhamento, construção de cultura política, redefinição do conceito de participação ;

- Luta dos professores e outros profissionais da educação por condições salariais e de trabalho;

- Lutas dos estudantes por vagas, condições, mensalidades, refeitórios, moradia, contra discriminações, etc.

\section{Conclusões e desafios}

Articular a educação, em seu sentido mais amplo, com os processos de formação dos indivíduos como cidadãos, ou articular a escola com a comunidade educativa de um território é um sonho, uma utopia, mas também uma urgência e uma demanda da sociedade atual. Por isso trabalhamos com um conceito amplo de educação que envolve campos diferenciados, da educação formal, informal e não-formal. Acreditamos que propostas se fazem com idéias e fundamentos; por isso, dedicamos a primeira parte do texto a qualificação e diferenciação de um conceito que tem centralidade no tema que estamos discutido, qual seja: a importância da educação não-formal.

Reiteramos neste texto a perspectiva que aborda a educação como promotora de mecanismos de inclusão social. Entende-se por inclusão as formas que promovem o acesso aos direitos de cidadania, que resgatam alguns ideais já esquecidos pela humanidade, como o de civilidade, tolerância e respeito ao outro; contestam-se concepções relativas às formas que buscam, simplesmente, integrar indivíduos atomizados e desterritorializados, em programas sociais compensatórios.

A gestão compartilhada em suas diferentes formas de conselhos, colegiados etc. precisa desenvolver uma cultura participativa nova, que altere as mentalidades, os valores, a forma de conceber a gestão pública em nome dos direitos da maioria e não de grupos lobbistas. Isso implica a criação de coletivos que desenvolvam saberes não apenas normativos - legislações, formatos de aplicação de verbas etc., embora esses itens também sejam importantes, dado o papel dos fundos públicos no campo de disputa política em torno das verbas públicas. É preciso desenvolver saberes que orientem as práticas sociais, que construam novos valores, aqui entendidos como a participação de coletivos de pessoas diferentes com metas iguais. Isto tudo está no campo da educação não-formal.

Entretanto, se não houver sentido nas formas de participação na área da educação, com projetos de emancipação dos cidadãos que objetivem mudanças substantivas e não instrumentais, corre-se o risco de se ter espaços mais autoritários do que já eram quando centralizados. Como democratizar esses espaços? Como ressignificá-los para que as obras e serviços realizados numa escola, por exemplo, não sejam vistos como dádivas de uma diretora, ou de algum político ou administrador público, e sim como direito da população? Como resgatar o direito à educa- 
ção enquanto política educacional ao nível das instâncias locais, sem esquecer que elas são parte de um todo que extrapola as fronteiras nacionais? Como gerar novas políticas na gestão dos fundos públicos?

São desafios e tarefas gigantescas. Não dá para contar apenas com heroísmos de alguns gestores públicos bem intencionados ou de poucas lideranças da sociedade civil, pois construir sentido e significados novos na gestão da escola é uma prática que tem que se pautar por um outro olhar em relação ao papel da escola num dado território. Não é mais possível permanecer no conformismo diante de espaços dominados por antigos métodos clientelistas, pela ordem tradicional. É preciso criatividade e ousadia porque as novidades só ganham força quando passam a ter hegemonia em certos coletivos organizados mais amplos. Por isso, é preciso voltar os olhos para a organização da sociedade civil, para os processos de educação não-formal que nela se desenvolvem, e para o papel que a escola pode ter como campo de formação de um novo modelo civilizatório. Precisamos de uma nova educação que forme o cidadão para atuar nos dias de hoje, e transforme culturas políticas arcaicas, arraigadas, em culturas políticas transformadoras e emancipatórias. Isso não se faz apenas em aulas e cursos de formação tradicionais, formulados no gabinete de algum burocrata, e sim a partir da prática da gestão compartilhada escola/comunidade educativa, no exercício das tarefas de que a conjuntura de uma dada escola, numa determinada comunidade territorial, necessite. Participar dos conselhos e colegiados das escolas é uma urgência e uma necessidade imperiosa, mas exige uma preparação contínua, um aprendizado permanente, uma atividade de ação e reflexão. Não basta um programa, um plano, ou mais um conselho. É preciso reconhecer a existência e a importância da educação não-formal no processo de construção de uma sociedade sem injustiças, democrática..

Construir cidadãos éticos, ativos, participativos, com responsabilidade diante do outro e preocupados com o universal e não com particularismos, é retomar as utopias e priorizar a mobilização e a participação da comunidade educativa na construção de novas agendas. Essas agendas devem contemplar projetos emancipatórios que tenham como prioridade a mudança social, qualifiquem seu sentido e significado, pensem alternativas para um novo modelo econômico não excludente que contemple valores de uma sociedade em que o ser humano é centro das atenções e não o lucro, o mercado, o status político e social, o poder em suma. A educação não - formal é um campo valioso na construção daquelas agendas, e para dar sentido e significado às próprias lutas no campo da educação visando à transformação da realidade social.

Concluímos este texto com uma proposta de caráter sociopolítico: a de transformar as escolas em centro de referências civilizatórias nos bairros onde se localizam. Para isso propomos a articulação dos processos de participação da sociedade civil organizada com as escolas. Propomos, em suma, a articulação da educação formal com a não-formal para dar vida e viabilizar mudanças significativas na educação e na sociedade como um todo. 


\section{Referências}

BAUMAN, Z. Community. Cambridge: Polity, 2001.

COLL, C. Educação, escola e comunidade: na busca de um compromisso. Pátio: revista pedagógica, Porto Alegre, ano 3, n. 10, p. 8-12, 1999.

FREIRE, P. Pedagogia do oprimido. Rio de Janeiro: Paz e Terra, 1980.

GOHN, M. G. Conselhos gestores e participação sociopolítica. 2. ed. São Paulo: Cortez, 2003.

. Educação não-formal e cultura política. 3. ed. São Paulo: Cortez, 2005.

. Movimentos e lutas sociais na História do Brasil. São Paulo: Loyola, 1995.

. Movimentos sociais e educação. 5. ed. São Paulo: Cortez, 2003.

. O protagonismo da sociedade civil: movimentos sociais, ONGs e redes solidárias. São Paulo: Cortez, 2005.

. Teoria dos movimentos sociais. 4. ed. São Paulo: Loyola, 2004.

HONNETH, A. Luta por reconhecimento:a gramática moral dos conflitos sociais. São Paulo: Ed. 34, 2003.

PUTNAM, R. D. Bowling alone. New York: Simon \& Schuster, 2000.

SANTOS, B. S. A crítica da razão indolente: contra o desperdício da experiência. São Paulo: Cortez, 2000.

SANTOS, B. S. (Org.). Democratizar a democracia: os caminhos da democracia participativa. Rio de Janeiro: Civilização Brasileira, 2002.

SENNET, R. A corrosão do caráter: conseqüências pessoais do trabalho no novo capitalismo. Rio de Janeiro: Record, 1999.

SILVA, P. Escola - família, uma relação armadilhada: interculturalidade e relações de poder. Porto: Afrontamento, 2003.

Recebido em: 27/07/2005

Aceito para publicação em: 13/02/2006 